\title{
Avaliação da sinérese em geléia de abacaxi por meio de análise uni e multivariada
}

\section{Jelly pineapple syneresis assessment via univariate and multivariate analysis}

\author{
Silvana Licodiedoff' ${ }^{1}$ Arislete Dantas de Aquino ${ }^{2}$; Rossana Catie Bueno de \\ Godoy $^{3}$; Carlos Alberto da Silva Ledo ${ }^{4}$
}

Resumo

\begin{abstract}
A avaliação da geléia de abacaxi visa analisar a ocorrência de sinérese através da análise uni e multivariada. A geléia de abacaxi apresenta baixo teor de pectina, portanto, adicionou-se pectinas de alta metoxilação nas seguintes concentrações $0,50 \% ; 0,75 \%$ e $1,00 \%$ que correspondem a lenta, média e rápida velocidade de geleificação. Neste estudo verificou-se o pH, acidez titulável, brix e a sinérese da geléia. A maior concentração de pectina na geléia apresentou uma diminuição na liberação de água, sinérese. Este resultado evidenciou que o percentual de 1,00\% da pectina na geléia é necessária para formar o gel e obter uma textura adequada.
\end{abstract}

Palavra-chave: Análise química. Sinérese. Análise de agrupamento.

\begin{abstract}
The evaluation of the pineapple jelly is intended to analyze the occurrence of syneresis by univariate and multivariate analysis. The jelly of the pineapple presents low concentration pectin, therefore, it was added high methoxyl pectin in the following concentrations: $0.50 \%, 0.75 \%$ and $1.00 \%$ corresponding to slow, medium and fast speed of gel formation process. In this study it was checked the $\mathrm{pH}$, acidity, brix and the syneresis of jelly. The highest concentration of pectin in the jelly showed a decrease in the release of the water, syneresis. This result showed that the percentage of $1.00 \%$ of pectin in jelly is necessary to form the gel and to obtain a suitable texture.
\end{abstract}

Key-words: Chemical analysis. Syneresis. Cluster analysis.

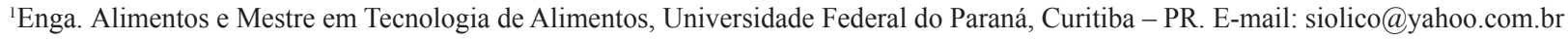
${ }^{2}$ Enga. Química e Docente do Departamento Engenharia Química da UFPR. E-mail: arislete@ufpr.br

${ }^{3}$ Enga. Agrônoma e Pesquisadora da Embrapa Floresta, Colombo - PR. E-mail: catie.godoy@gmail.com

${ }^{4}$ Eng. Agrônomo e Pesquisador da Embrapa Mandioca e Fruticultura Tropical, Cruz das Almas - BA.E-mail: ledo@cnpmf.embrapa.br 


\section{Introdução}

O abacaxi apresenta-se como um autêntico fruto das regiões tropicais e subtropicais, bastante consumido mundialmente (GRANADA; ZAMBIAZI; MENDONÇA, 2004). Seu sabor e aroma característicos se devem à presença de vários constituintes, destacando-se principalmente a sacarose e os ácidos cítrico e málico. Destaca-se, também, pelo seu valor energético, devido à sua alta composição de açúcares, e valor nutritivo pela presença de sais minerais (cálcio, fósforo, magnésio, potássio, sódio, cobre e iodo) e de vitaminas $\mathrm{C}, \mathrm{A}$, B1, B2 e Niacina (THÉ, 2007).

Mesmo com baixo teor de pectina, o abacaxi é adequado para a fabricação de geléias devido ao seu alto teor de ácido naturalmente presente na fruta, esta característica por sua vez contempla as exigências mínimas para a fabricação de geléias cujo processo requer a presença de ácidos para a formação do gel. Em frutas de baixa acides é necessária a adição de ácidolantes (SILVA, 2006).

Por definição, geléia compreende produtos preparados a partir de frutas e/ou sucos, misturados com açúcar com adição de pectina, ácidos e outros ingredientes permitidos, podendo apresentar frutas inteiras, partes e/ou pedaços sob variadas formas, as quais serão processadas até se obter uma concentração e consistência semi-sólida adequada (PEREDA et al., 2005).

De maneira geral, o gel envolve a pectina, o açúcar e o ácido (LÜCK; JAGER, 2000). Em valores críticos de $\mathrm{pH}$ baixo bem como a adição de pectina em quantidade insuficiente podem promover a sinérese que é a exudação do líquido da geléia (JACKIX,1988; CP KELCO, 2001).

Segundo a resolução RDC no 65 de 2007 da ANVISA (BRASIL, 2007), a pectina pode ser adicionada na fabricação de geléias em quantidades suficientes à promoção do gel. No caso de frutas naturalmente ricas em pectinas esse aditivo deve ser utilizado em quantidades minimas podendo até mesmo ser dispensado. Para tanto o objetivo do presente trabalho foi avaliar a influência da adição de pectina comercial em relação à sinérese na geléia de abacaxi através das análises físico-químicas, uni e multivariadas.

\section{Material e métodos}

O experimento foi realizado no laboratório de Tecnologia de Alimentos da Universidade Federal do Paraná. As geléias foram elaboradas utilizando-se frutos de abacaxizeiro da cultivar Smooth Cayenne (oriundos de Tocantins, adquiridos no Ceasa/PR), pectina (fornecida pela empresa $\mathrm{Cp} \mathrm{Kelco/SP)} \mathrm{e}$ sacarose comercial.

\section{Preparo das geléias}

Os frutos foram lavados e descascados. Em seguida, retiraram-se os frutilhos e a parte central. As fatias foram cortadas manualmente e moídas em um processador. $\mathrm{O}$ processo da geléia seguiu as etapas representadas na (Figura 1).

As formulações foram elaboradas utilizando-se a relação 2:3 de polpa e açúcar, $\mathrm{pH}$ de 3,7. Os produtos

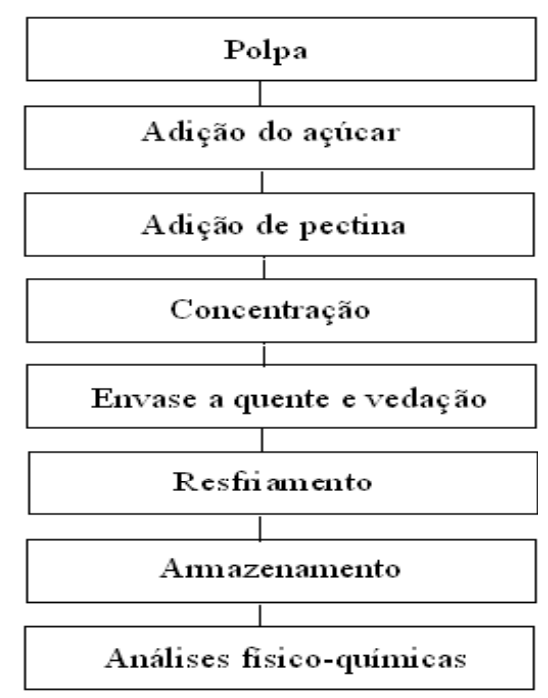

Figura 1. Fluxograma correspondente ao processamento da geléia de abacaxi 
foram elaborados com pectinas de alta metoxilação variando-se a velocidade de geleificação (lenta, média e rápida) e três níveis de concentração $(0,50$; $0,75$ e $1,00 \%)$, totalizando nove tratamentos.

A evaporação foi conduzida até atingir a concentração de $68^{\circ}$ Brix, quando procedeu-se o envase a quente, com posterior resfriamento. Os produtos foram acondicionados em embalagens de vidro, previamente esterilizadas a $100^{\circ} \mathrm{C} / 15 \mathrm{~min}$ com capacidade para $150 \mathrm{~g}$, fechados com tampa de metal e armazenados a temperatura ambiente.

\section{Análises físico-químicas}

As análises físico-químicas foram realizadas no primeiro, quarto e sétimo mês.

\section{Sólidos solúveis totais}

O teor de sólidos solúveis totais na polpa de abacaxi e nas geléias foi determinado utilizandose um refratômetro de bancada (RL3 - Polskie Zaklandy Optyczne S.A), com escala de 0 a $90^{\circ}$ Brix e correção da temperatura para $20{ }^{\circ} \mathrm{C}$ conforme método $\mathrm{n}^{\circ}$ 13.6.1 de acordo com Brasil (2005).

\section{Acidez total titulável}

A acidez total titulável das amostras foi quantificada por titulação com solução padronizada de hidróxido de sódio utilizando solução alcoólica de fenolftaleína a $1 \%$ como indicador, conforme especificado pelo método $\mathrm{n}^{\circ}$ 13.6.2 de acordo com Brasil (2005) Os resultados foram expressos em porcentagem de ácido cítrico.

$p H$

A determinação do $\mathrm{pH}$ realizou-se através do método potenciométrico, calibrando-se o equipamento (ORION modelo 710A) com soluções tampão ( $\mathrm{pH} 4,0$ e 7,0 ), a $25^{\circ} \mathrm{C}$, imergindo-se em seguida o eletrodo no béquer com a amostra, expressando-se os resultados em unidades de $\mathrm{pH}$ (BRASIL, 2005)

\section{Sinérese}

A presença de sinérese na geléia de abacaxi foi determinada por gravimetria utilizando-se um béquer de $250 \mathrm{~mL}$ e uma peneira comum (CP KELCO, 2007) . O volume de líquido depositado no fundo do béquer foi pesado e utilizado para o cálculo da porcentagem de sinérese de acordo com a (Eq. 1) (KHOURYIER; ARAMOUNI; HERALD, 2005). Os resultados foram expressos em gramas de líquido liberado/100g de produto.

Sinérese $\cdot(\%)=\frac{\text { gramas } \cdot \text { de } \cdot \text { líquido } \cdot \text { liberado } \times 100}{100 \mathrm{~g} \cdot(\text { total } \cdot \text { da } \cdot \text { amostra })}$

(Eq. 1)

\section{Delineamento estatístico}

Para os dados obtidos foram realizadas análises uni e multivariada. Para a análise univariada foi realizada a análise de variância considerando o modelo estatístico do delineamento inteiramente casualizado, com 9 tratamentos e 3 repetições, no esquema de parcela subdividida no tempo. Os tratamentos foram representados por um arranjo fatorial $3 \times 3$, sendo 3 tipos de pectinas e 3 níveis de concentração (PIMENTEL, 2000). As médias dos tratamentos foram comparadas pelo teste de Tukey a 5\% de probabilidade. As análises estatísticas univariadas foram realizadas utilizando-se o programa SISVAR (FERREIRA, 2000).

Para a análise multivariada de agrupamento adotou-se como medida de dissimilaridade a distância euclidiana média e para a formação dos grupos utilizou-se o método UPGMA (unweighted pairgroup means average). $\mathrm{O}$ número de grupos foi definido pela média da matriz de agrupamento. A contribuição relativa de cada variável foi calculada pelo método de Singh (1981). As análises estatísticas foram realizadas utilizando-se os programas Genes 
(CRUZ, 2001) e Statistica (STATSOFT INC., 2005).

Todas as determinações nas amostras foram conduzidas em triplicata.

\section{Resultados e discussão}

Houve efeito significativo da interação entre concentração $\mathrm{x}$ tipo de pectina para as variáveis sólidos solúveis totais, acidez total titulável e sinérese $(\mathrm{p}<0,05)$. Não houve significância de nenhum fator para a variável $\mathrm{pH}(\mathrm{p}>0,05)$. Os coeficientes de variação apresentaram valores de 1,02 a 7,48\% para as variáveis de sólidos solúveis totais e acidez total titulável, respectivamente Tabela 1 .

Tabela 1 - Valores médios das variáveis sólidos solúveis totais, $\mathrm{pH}$, acidez total titulável e sinérese em função do tipo e da concentração de pectina.

\begin{tabular}{|c|c|c|c|}
\hline \multirow{2}{*}{$\begin{array}{l}\text { Pectinas de alta } \\
\text { metoxilação }\end{array}$} & \multicolumn{3}{|c|}{ Concentração (\%) } \\
\hline & 0,50 & 0,75 & 1,00 \\
\hline \multicolumn{4}{|c|}{ Sólidos solúveis totais $\left({ }^{\circ} \mathrm{Brix}\right)$} \\
\hline Rápida geleificação & $69,6667 \pm 0,6614 \mathrm{aA}$ & $65,0000 \pm 0,5000 \mathrm{cC}$ & $67,3333 \pm 0,8660 \mathrm{aB}$ \\
\hline Média geleificação & $66,0000 \pm 0,8660 \mathrm{cB}$ & $67,6667 \pm 1,0000 \mathrm{aA}$ & $67,5000 \pm 0,7500 \mathrm{aA}$ \\
\hline Lenta geleificação & $67,8333 \pm 1,3229 \mathrm{bA}$ & $66,3333 \pm 0,5000 \mathrm{bB}$ & $68,0000 \pm 0,5000 \mathrm{aA}$ \\
\hline $\mathrm{CV}(\%)$ & & & 1,02 \\
\hline \multicolumn{4}{|c|}{$\mathrm{pH}$} \\
\hline Rápida geleificação & $3,0744 \pm 0,3078 \mathrm{aA}$ & $3,0878 \pm 0,2936 \mathrm{aA}$ & $3,1144 \pm 0,2887 \mathrm{aA}$ \\
\hline Média geleificação & $3,0989 \pm 0,2955 \mathrm{aA}$ & $3,1144 \pm 0,3106 \mathrm{aA}$ & $3,1100 \pm 0,3075 \mathrm{aA}$ \\
\hline Lenta geleificação & $3,1222 \pm 0,3365 \mathrm{aA}$ & $3,1244 \pm 0,3259 \mathrm{aA}$ & $3,1133 \pm 0,2971 \mathrm{aA}$ \\
\hline $\mathrm{CV}(\%)$ & & & 1,81 \\
\hline \multicolumn{4}{|c|}{ Acidez total titulável (g ác. cítrico/ $100 \mathrm{~g}$ ) } \\
\hline Rápida geleificação & $0,3389 \pm 0,4076 \mathrm{bA}$ & $0,3156 \pm 0,2333 \mathrm{bA}$ & $0,2711 \pm 0,4428 \mathrm{aB}$ \\
\hline Média geleificação & $0,3478 \pm 0,2603 \mathrm{aA}$ & $0,3644 \pm 0,1986 \mathrm{aA}$ & $0,3556 \pm 0,2774 \mathrm{aA}$ \\
\hline Lenta geleificação & $0,3389 \pm 0,2565 \mathrm{bA}$ & $0,3433 \pm 0,2499 \mathrm{abA}$ & $0,3433 \pm 0,3839 \mathrm{aA}$ \\
\hline $\mathrm{CV}(\%)$ & & & 7,48 \\
\hline \multicolumn{4}{|c|}{ Sinérese ( $\mathrm{g} \mathrm{H}_{2} \mathrm{O} / 100 \mathrm{~g}$ produto) } \\
\hline Rápida geleificação & $3,7000 \pm 0,8643 \mathrm{aA}$ & $1,0800 \pm 1,1541 \mathrm{bB}$ & $0,2433 \pm 0,8643 \mathrm{bB}$ \\
\hline Média geleificação & $2,9767 \pm 0,8224 \mathrm{aA}$ & $2,4733 \pm 0,5659 \mathrm{aA}$ & $1,2600 \pm 0,9925 \mathrm{aB}$ \\
\hline Lenta geleificação & $3,5400 \pm 1,0263 \mathrm{aA}$ & $2,3600 \pm 0,3753 \mathrm{aB}$ & $1,4767 \pm 0,2391 \mathrm{aB}$ \\
\hline $\mathrm{CV}(\%)$ & & & 2,12 \\
\hline
\end{tabular}

Médias seguidas pela mesma letra minúscula nas colunas e maiúsculas nas linhas não diferem estatisticamente entre si pelo teste de Tukey a 5\% de probabilidade.

Verifica-se pela Tabela 1 que, o maior teor de sólidos solúveis totais $(69,67)$ foi obtido com o uso de pectina de alta metoxilação e rápida geleificação na concentração de $0,50 \%$. Este resultado foi semelhante aos valores encontrados por Freitas, Candido e Silva (2008), cujos teores de sólidos solúveis totais variaram de 65,08 a 68,63 para a geléia de gabiroba elaborada com pectina comercial na mesma concentração. Enquanto que para o pH o menor valor encontrado $(3,07)$ foi no tratamento com a concentração de $0,50 \%$ e o maior com concentração de $1,00 \%$ para a mesma pectina. Godoy, Antunes e Zonta (1998) avaliaram a influência da adição de hidrocolóides (goma xantana, carragena e amido ceroso) na composição físico-química de néctar de goiaba e verificaram aumentos significativos nos valores do $\mathrm{pH}$ à medida que se utilizaram maiores concentrações destes aditivos. 
O menor percentual de água liberada (sinérese) $(0,2433)$ foi encontrado na geléia de abacaxi com o uso da pectina de alta metoxilação e rápida geleificação na concentração de $1 \%$.

Pela Tabela 2 verifica-se que as variáveis sólidos solúveis totais e sinérese foram as que mais contribuíram para explicar a variação total disponível com valores de 56,35\% e 43,62\%, respectivamente.

Tabela 2 - Contribuição relativa de cada variável segundo o método de Singh (1981).

\begin{tabular}{lcc}
\hline Variável & S.j & Valor $(\%)$ \\
\hline $\begin{array}{l}\text { Sólidos } \\
\text { solúveis totais }\end{array}$ & 130,0579 & 56,3491 \\
pH & 0,0196 & 0,0085 \\
Acidez total & 0,0548 & 0,0237 \\
titulável & & \\
Sinérese & 100,675 & 43,6186 \\
\hline
\end{tabular}

Pelo dendrograma (Figura 2), verifica-se a formação de 4 grupos: o primeiro formado pelo tratamento 1 (pectina de rápida geleificação na concentração $0,50 \%$ ); o segundo grupo formado pelos tratamentos 2, 3, 5, 6, 8 e 9; o terceiro grupo formado pelo tratamento 4 (pectina de rápida geleificação na concentração $0,75 \%$ ); e um quarto grupo formado pelo tratamento 7 (pectina de rápida geleificação na concentração 1,00\%). $\mathrm{O}$ primeiro grupo se caracteriza pelos tratamentos que propiciaram os maiores valores de sólidos solúveis totais, $(69,67)$ e sinérese, $(3,70)$. O terceiro grupo tem por característica os tratamentos que propiciaram os menores valores de sólidos solúveis totais, $(65,00) ; \mathrm{pH},(3,09)$; acidez total titulável, $(0,32)$; e sinérese, $(1,08)$ Tabela 1 . O coeficiente de correlação cofenético foi de $0,91 * *$, indicando alta correlação entre as matrizes de dissimilaridade e de agrupamento.

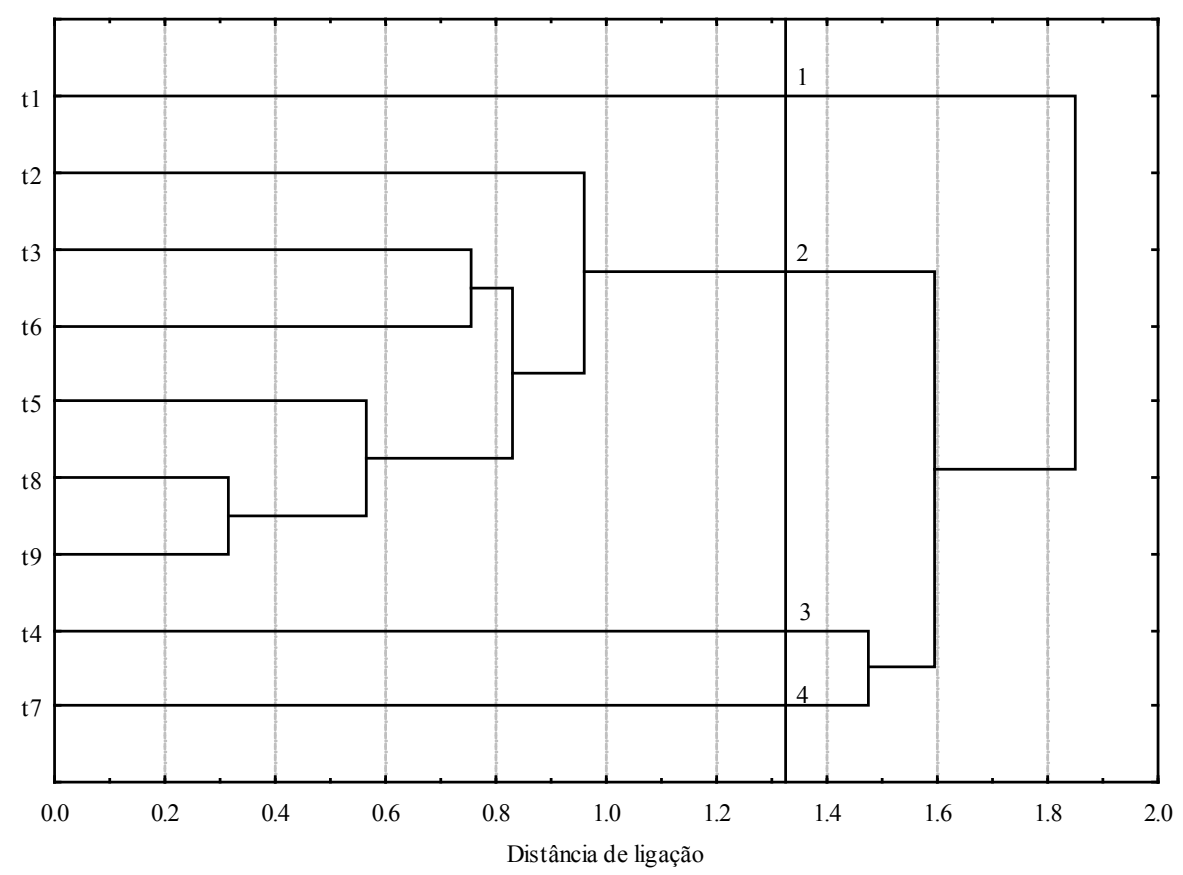

Figura 2. Dendrograma de dissimilaridade para os 9 tratamentos com base nas variáveis sólidos solúveistotais, $\mathrm{pH}$, acidez total titulável e sinérese. $\mathrm{t} 1$ = pectina de rápida geleificação na concentração $0,50 \%$; 2 = pectina de média geleificação na concentração $0,50 \%$; t3 = pectina de lenta geleificação na concentração $0,50 \% ; \mathrm{t} 4$ = pectina de rápida geleificação na concentração $0,75 \%$; t5 = pectina de média geleificação na concentração $0,75 \%$; t6 = pectina de lenta geleificação na concentração $0,75 \%$; 7 = pectina de rápida geleificação na concentração $1,00 \%$; t8 $=$ pectina de média geleificação na concentração $1,00 \%$; 9 = pectina de lenta geleificação na concentração $1,00 \%$. 


\section{Conclusões}

As geléias de abacaxi apresentaram comportamento diferenciado quando elaboradas com pectinas distintas em sua concentração;

A partir dos resultados obtidos constatou-se que a geléia de abacaxi elaborada com pectina de alta metoxilação e rápida geleificação na concentração de $1,00 \%$ apresentou os menores valores de sinérese, sendo desta forma a mais recomendada para este tipo de produto.

\section{Agradecimentos}

À Coordenação de Aperfeiçoamento de Pessoal de Nível Superior (Capes), pela bolsa de Mestrado.

\section{Referências}

BRASIL. Agência Nacional de Vigilância Sanitária. Resolução - RDC ANVISA/MS no 65, de 04 de outubro de 2007. Atribuição de aditivos alimentares, suas funções e seus limites máximos para geléias de frutas, vegetais, baixa caloria e mocotó. Diário Oficial da União. Brasília, DF, 4 out. 2007. Seção 1.

BRASIL. Ministério da Saúde. Agência Nacional de Vigilância Sanitária. Métodos físico-químicos para análise de alimentos. Brasília: Ministério da Saúde, 2005. (Série A. Normas e Manuais Técnicos - Instituto Adolfo Lutz; 4).

CP KELCO. A Huber Company. Troubleshooting of jams, jellies, marmalades and preserves: aplication note. Atlanta: USA, Apr. 2001.

CP KELCO BRASIL S/A. Pectinas: especificações técnicas. Limeira: CP KELCO, 2007.

CRUZ, C. D. Programa genes: versão windows; aplicativo computacional em genética e estatística. Viçosa: UFV, 2001.

FERREIRA, D. F. Análises estatísticas por meio do Sisvar para Windows versão 4.0. In: REUNIÃO ANUAL DA REGIÃO BRASILEIRA DA SOCIEDADE INTERNACIONAL DE BIOMETRIA, 45., 2000, São Carlos. Resumos... São Carlos: UFSCar, 2000. p. 255258.
FREITAS, J. B.; CANDIDO, T. L. N.; SILVA, M. R. Geléia de gabiroba: avaliação da aceitabilidade e características físicas e químicas, Goiânia. Pesquisa Agropecuária Tropical, Goiânia, v. 38, n. 2, p. 87-94, 2008.

GODOY, R. C. B.; ANTUNES, P. L.; ZONTA, W. P. Estabilização de néctar de goiaba (Psidium guayava L.) com gomas xantana, carragena e amido ceroso. Revista Brasileira de Agrociência, Pelotas, v. 2, n. 2, p.105-110, 1998.

GRANADA, G. G.; ZAMBIAZI, R. C.; MENDONÇA, C. R. B. Abacaxi: produção, mercado e subprodutos. Boletim CEPPA, Curitiba, v. 22, n. 2, p. 405-422, 2004.

JACKIX, M. H. Doces, geléias e frutas em calda. Campinas: Unicamp, 1988. (Série Tecnologia de Alimentos).

KHOURYIER, H. A.; ARAMOUNI, F. M; HERALD, T. J. Physical, chemical and sensory properties of sugar-free jelly, Manhattan. Journal of Food Quality, Wastport, v. 28, n. 2, p. 179-190, 2005.

LÜCK, E.; JAGER, M. Conservación química de los alimentos: características, usos, efectos. Zaragoza: Acribia, 2000.

PEREDA, J. A. O.; RODRÍGUES, M. I. C.; ÁLVAREZ, L. F.; SANZ, M. L. G.; MINGUILLÓN, G. D. G. F.; PERALES, L. H.; CORTECERO, M. D. S. Tecnologia de alimentos. Porto Alegre: Artmed, 2005. v. 1.

PIMENTEL G. F. Curso de estatística experimental. 14. ed. Piracicaba: Nobel, 2000.

SILVA, A. C. A. Serviço Brasileiro Resposta Técnica SBRT. Porto Alegre: SENAI-RS, 2006.

SINGH, D. The relative importance of characters affecting genetic divergence. Indian Journal of Genetics and Plant Breeding, New Delhi, v. 41, p. 237-245, 1981.

STATSOFT, Inc. Statistica for windows (data analysis software system), version 7.1. Tulsa: Statsoft, 2005.

THÉ, P. M. P. Quais as propriedades medicinais do abacaxi? Revista Ciência Hoje, Fortaleza, v. 39, n. 4, p. 200-229, 2007.

Recebido em 29 Outubro, 2009 - Received on October 29, 2009. Aceito em 19 Fevereiro, 2010 - Accepted on February 19, 2010. 